\title{
Fishery share systems, ITQ and the distribution of rents
}

\author{
Aaron Hatcher \\ University of Portsmouth, UK
}

\begin{abstract}
Although, in most commercial fisheries, fishing crews are remunerated under a share system, the implications of share systems for ITQ markets have received relatively little attention. In this paper we model the impact of extending crew shares of vessel operating costs to include payments for quota. Allocative efficiency is maintained as long as any share system is adopted consistently across the entire fleet. Making crews bear a share of quota costs, however, simply inflates the quota price: at market equilibrium the vessel owner's profit share is unaffected. Crews lose out if the vessel is leasing quota in, but gain if the vessel owner is a net seller of quota. We also consider the outcome if only net purchasers of quota involve crews in the cost of quota. Here, all vessel owners benefit, while all crews see a reduction in their earnings. These results are illustrated with a simple numerical example.
\end{abstract}

Keywords: fisheries; ITQs; quota markets; share payments; resource rent 


\section{Introduction}

In many, if not most, commercial fisheries, fishing crews are rewarded under a share or "lay" system (Sutinen, 1979; Anderson, 1982; Matthiasson, 1999; McConnell and Price, 2006). Despite this, most economic models of the fishery either treat labour costs in a similar way to other variable costs, i.e., as related to harvest or fishing effort, or assume (implicitly) that labour is paid a fixed wage. If instead there is a share system of crew remuneration, and owners of fishing firms make decisions based only upon their shares of the costs and benefits to the firm, this can have significant implications for economic outcomes in the fishery.

A case in point is the use of ITQs (individual transferable quotas) in fisheries management. ITQ systems are now widely employed in commercial fisheries in order to achieve efficient regulation of harvest. Although, in almost all such fisheries, crews are remunerated using a share system, it is common for quota costs to be borne entirely by the vessel owner, as is the case in Iceland and Australia, for example. In some instances, however, the fact that payments for quota leasing appear as additional financial costs to the firm has led to a practice of sharing quota costs between owner and crew, along with other variable operating costs. This is now the norm in the UK, for example, where revenues and operating costs (including the costs of quota leasing) are generally split 50:50 between owner and crew. ${ }^{1}$ It is not immediately clear, however, what consequences this has for the economic performance of the fleet and for the earnings of vessel owners and their crews. Empirical studies of crew remuneration under ITQ systems have reported both negative (Pinkerton and Edwards, 2009) and positive (Abbott, Garber-Yonts and Wilen, 2010) income effects due to the introduction of ITQs, but there appears to be no record of the impact of changes in crews' shares of quota costs under an existing ITQ regime.

The aim of this paper is to examine the implications of sharing the cost of quota for the generation and distribution of economic profits in an ITQ fishery. Although there is now a large theoretical literature on ITQs, relatively few authors have considered the implications of share payments for the properties of ITQ markets. Anderson (1999) examines the long run efficiency of the fleet under an ITQ system when the crew are paid on a share basis, concluding that full efficiency in the long run can only be achieved if the vessel owner and the crew have equal shares of both quota costs and what we will refer to as "operating profits" (revenues minus non-labour variable costs). If owners pay all the quota costs, long run efficiency cannot be achieved, it is held, since individual owners under-invest, vessels harvest too little and the fleet will be too large as a consequence. Hannesson (2000) finds that the vessel owner's decision to invest in ITQs under a share system is distorted if a share of profits is paid to the crew, and argues that over-investment in physical capital may occur as a result. McConnell and Price (2006) consider the allocative efficiency of ITQs with a

\footnotetext{
${ }^{1}$ Although the UK does not have a formal ITQ system as such, the arrangements for devolved quota management allow a significant amount of quota trading to take place in practice, particularly in the in-year (lease) market.
} 
share system and show that the quota market will be inefficient if the owner's shares of revenues and non-labour harvesting costs diverge. These authors do not, however, examine the implications of crew shares for the generation and distribution of rents under an ITQ system. Only Anderson (1999) explicitly considers the relationship between the share rate and the price at which quota is traded between vessels, but he does so in the context of a long run industrial equilibrium, with adjustments in both fleet and stock size, and with identical shares pertaining for both quota costs and operating profits throughout.

The focus in this paper is on the relative share rates for quota costs and operating profits, rather than the share rate per se, and the impact these have on economic profits and the quota price, as well as the earnings by owner and crew. We find that the equilibrium quota price is sensitive to the difference between the owner's share of operating profits and his share of quota costs. While this may not be unexpected, what is perhaps less intuitive is that changes in the owner's share of the cost of quota have no effect upon his total profit share when shares are the same across the entire fleet. All the impacts of resultant changes in the quota price are felt by the crew, who experience a loss or gain in income as a result. We also examine a situation in which net sellers of quota are reluctant to share quota income with the crew, while net purchasers of quota share their quota costs. Here we find that both categories of vessel owner are better off under a sharing arrangement, whereas both crews see a loss in income.

The paper proceeds as follows. Section 2 sets up a model of a fishing firm in an ITQ market with crew shares. The implications of crew shares of quota costs are then explored in the following two sections, firstly assuming that shares are the same for all vessels in the fleet and then assuming that only firm owners who are net purchasers of quota share quota costs. Section 5 provides a simple numerical illustration of the results, while a final section concludes.

\section{A fishing firm model with ITQs and crew shares}

Consider an ITQ fishery made up of a large number of price taking fishing firms. For simplicity, we will assume that each firm operates a single fishing vessel. For a representative firm, total short run profits as a function of harvest $q_{i}$ and quota demand $Q_{i}$ are given by

$$
B_{i}\left(q_{i}\right)-r\left[Q_{i}-\bar{Q}_{i}\right],
$$

where $r$ is the equilibrium quota rental (lease) price and $\bar{Q}_{i} \geq 0$ is the firm's initial quota endowment (or, equivalently, the quantity of quota held by the firm as an asset). The private benefit (or "operating profits") function $B_{i}\left(q_{i}\right)$ is defined as

$$
B_{i}\left(q_{i}\right) \equiv p q_{i}-c_{i}\left(q_{i}\right),
$$

where $p$ is the market price for output and $c_{i}\left(q_{i}\right)$ are (non-labour) variable harvesting costs. As is usual, we assume convex costs, so that $c_{i}^{\prime \prime}\left(q_{i}\right)>0$ and hence $B_{i}^{\prime \prime}\left(q_{i}\right)<0$. 
Let the firm owner's shares of operating profits and quota lease costs be given by $0<\alpha_{i}<1$ and $0<\gamma_{i} \leq 1$ respectively. The crew's shares of operating profits and quota costs are therefore $0<\left[1-\alpha_{i}\right]<1$ and $0 \leq\left[1-\gamma_{i}\right]<1$. We assume throughout that the crew's reservation wage remains constant and is always met, i.e., labour's participation constraint is never binding. The total quantity of labour is, as a consequence, unchanged. For simplicity, therefore, the opportunity cost of crew labour is not explicitly included in the model. ${ }^{2}$

Assuming quota compliance, the owner's short run profit maximisation problem is then

$$
\max _{q, Q} \quad \pi_{i}^{o} \equiv \alpha_{i} B_{i}\left(q_{i}\right)-\gamma_{i} r\left[Q_{i}-\bar{Q}_{i}\right], \quad \text { s.t. } \quad q_{i} \geq 0, Q_{i} \geq 0, Q_{i} \geq q_{i} .
$$

From the first order (Kuhn-Tucker) conditions for a solution to (3), it is straightforward to find the owner's optimal decision rule for $q_{i}^{*}=Q_{i}^{*}>0$ as

$$
B_{i}^{\prime}\left(q_{i}^{*}\right)=\frac{\gamma_{i}}{\alpha_{i}} r
$$

where $B_{i}^{\prime}\left(q_{i}^{*}\right) \equiv p-c_{i}^{\prime}\left(q_{i}^{*}\right)$. Unless $\gamma_{i}=\alpha_{i}$, this expression differs from the usual result for a competitive quota or permit market, which is the equality of marginal (social) benefits with the equilibrium lease price of permits/quota. Clearly, for marginal benefits (and hence marginal costs) to be equated across all firms in the fishery, we require either $\gamma_{i}=\alpha_{i}$ for each firm, or, if $\gamma_{i} \neq \alpha_{i}$, for the shares $\alpha$ and $\gamma$ to be the same for all firms. Otherwise, the quota allocation will not be efficient (except by chance).

In order to examine the quota market implications of different share arrangements, we go on to consider two scenarios: firstly, one in which any change in the owner's quota share relative to his share of operating profits occurs across all firms symmetrically; secondly, one in which a change in the owner's quota share affects only some firms in the fleet. In each case, we assume that the size of the fleet remains unchanged.

\section{Crew shares are the same for all firms}

To begin with, we assume that at quota market equilibrium the shares $\alpha$ and $\gamma$ are the same across all firms in the fleet. We can therefore treat a single firm as a model for the entire fleet, in the sense that the same equilibrium conditions containing $\alpha$ and $\gamma$ hold for all firms (there is no requirement for symmetry in the cost functions, for example). ${ }^{3}$ Note that heterogeneity in quota endowments is sufficient to generate trade in quota.

Suppose we have $\gamma>\alpha$ and hence, from equation (4), $B^{\prime}\left(q^{*}\right)>r$. This implies that the equilibrium quota price is less than the marginal benefit of harvest to the firm. Not surprisingly, if the owner bears a disproportionately

\footnotetext{
${ }^{2}$ Omitting the opportunity cost of labour from the benefit function means that total short run social benefits are overstated, but this makes no difference to our analysis.

${ }^{3}$ Individual subscripts are dropped accordingly.
} 
large share of the cost of quota, quota is traded at below its marginal value to the firm as a whole. If $\gamma<\alpha$, on the other hand, then $B^{\prime}\left(q^{*}\right)<r$ and quota is effectively overvalued with respect to its marginal benefit to the firm.

Totally differentiating (4) and rearranging, we obtain an expression for the slope of the owner's quota demand as

$$
\frac{d Q(r)}{d r}=\frac{d q(r)}{d r}=\frac{\gamma}{\alpha} B^{\prime \prime-1}(\cdot)<0,
$$

where $B^{\prime \prime-1}(\cdot)$ is the slope of the inverse of $B^{\prime}(q) .{ }^{4}$ All else equal, therefore, the greater is the owner's share $\gamma$ in the cost of quota, the steeper is his quota demand function and hence the lower is his demand for quota at any given quota price. As a result, the industry inverse quota demand will have a shallower slope as $\gamma$ increases and a steeper slope as $\gamma$ is reduced. For a given total quota supply (total allowable catch or TAC), therefore, the industry equilibrium quota price is reduced (increased) if $\gamma$ is increased (reduced) relative to $\alpha$. Changes in both $\gamma$ and $\alpha$ which leave the ratio $\gamma / \alpha$ unaltered, on the other hand, will have no effect upon individual quota demands and hence no effect upon the equilibrium quota price.

Notice that, given the concavity in the benefit function, $\gamma \neq \alpha$ in (4) seems to imply that total firm profits are not maximised by the firm owner: from (1) we would expect total profits for both owner and crew to be maximised where $B^{\prime}\left(q^{*}\right)=r$. If, instead, the firm operates where $B^{\prime}\left(q^{*}\right)>r$ for example, it appears to underproduce for the observed quota price. But in this case, as we have seen, the equilibrium quota price will be lower than it would be if all firms set $B^{\prime}\left(q^{*}\right)=r$. All else equal, if the quota market clears and the quota allocation continues to be efficient (as we have shown for symmetry in shares) then output for the representative firm is unchanged by a change in $\gamma$ and hence a change in the quota price $r$. Therefore, total economic profits are unaffected by an increase or a decrease in $\gamma$, holding $\alpha$ constant: there is simply a concomitant reduction or increase in the value of quota.

In order to examine this further, let $\tilde{r}$ be the equilibrium quota price when $\tilde{\gamma}=1>\alpha$ (the owner bears all quota costs). Then from (4) we have

$$
\left.B^{\prime}\left(q^{*}\right)\right|_{1=\gamma>\alpha}=\frac{\tilde{\gamma}}{\alpha} \tilde{r}=\frac{1}{\alpha} \tilde{r} .
$$

If we now reduce $\gamma$ from $\gamma=1$ to $\gamma=\alpha$, holding $\alpha$ constant, we will then have a quota price $r$ such that

$$
\left.B^{\prime}\left(q^{*}\right)\right|_{\gamma=\alpha}=\frac{\gamma}{\alpha} r=r .
$$

If there is no change in the output of the representative firm, as we have argued, then

$$
\left.B^{\prime}\left(q^{*}\right)\right|_{1=\gamma>\alpha}=\left.B^{\prime}\left(q^{*}\right)\right|_{\gamma=\alpha}
$$

\footnotetext{
${ }^{4}$ We assume that, for all $q \geq 0$, the function $B^{\prime}(q)$ has an inverse $B^{\prime-1}($.$) . By the inverse$ function rule, we then have $B^{\prime \prime}-1(.) \equiv 1 / B^{\prime \prime}(q)$.
} 
and therefore

$$
\frac{1}{\alpha} \tilde{r}=r
$$

which implies $r>\tilde{r}$. The quota price is therefore increased by the reduction in $\gamma$.

Suppose, in this example, that the firm is a net purchaser of quota, i.e., $Q^{*}>\bar{Q}$. When $\tilde{\gamma}=1$, the cost to the owner of a unit of quota is $\tilde{\gamma} \tilde{r}=\tilde{r}$. If $\gamma$ is then reduced to $\gamma=\alpha$, the owner's unit quota costs are now $\gamma r$. But, if $\alpha$ is unchanged, we can observe that

$$
\gamma r=\gamma \frac{1}{\alpha} \tilde{r}=\tilde{r}=\tilde{\gamma} \tilde{r}
$$

Hence, if $q^{*}=Q^{*}$ has not changed, the owner's quota costs have not changed. Since there has also been no change in the owner's share of operating profits $\alpha$, we can see that making the crew pay a share of the quota costs merely inflates the quota price at their expense: at quota market equilibrium there is no net gain to the firm owner.

We get the opposite result if $\gamma$ is increased from $\gamma=\alpha<1$ to $\gamma=1$, again holding $\alpha$ constant. Now, if the firm is a net purchaser of quota, we will see a reduction in the equilibrium quota price and an increase in crew remuneration. This represents a transfer from the total cost of quota to the total earnings of the crew.

It is straightforward to show that if the firm is a net seller of quota (and we assume that the income from leasing out quota is shared pro rata with the crew - see Section 4) then the impacts on crew remuneration from a change in $\gamma$ are simply reversed. Thus, all else equal, an increase in $\gamma$ results in a reduction in both total quota income and total crew remuneration, while a reduction in $\gamma$ produces an increase in total quota income and crew remuneration. At market equilibrium, therefore, sharing the income from quota leasing with the crew has no net negative impact upon the owner's profits.

In each case, with $\gamma$ and $\alpha$ the same across all firms in the fleet, the allocation of quota continues to be efficient. While the total value of quota changes with changes in $\gamma$ relative to $\alpha$, therefore, total economic profits in the fishery remain unaltered..$^{5}$

\section{Crew quota shares differ across firms}

Although sharing the cost of quota with the crew has no impact upon the owner's total share of the profits (operating profits less quota costs, or plus quota income) when all firms behave symmetrically, clearly there is an incentive for individual owners whose quota endowments are such that they are net sellers

\footnotetext{
${ }^{5}$ Given our very simple industry model, we have abstracted from the implications of firm heterogeneity, differences in factor cost/productivity and (hence) inframarginal rents. Economic profits may therefore be considered synonymous with resource rent.
} 
of quota to retain a $100 \%$ share of quota income. We therefore examine the quota market outcome if only net buyers of quota reduce the owner's quota share $\gamma$.

Consider a fishing fleet consisting of just two representative (price-taking) firms. Although we will assume for the moment that the firms are otherwise identical, we let the quota endowments $\bar{Q}_{i}$ be such that Firm 1 leases quota to Firm $2 .{ }^{6}$ Let the initial quota shares (the same for both firms) be $\gamma_{i}=1>$ $\alpha_{i}, i=1,2$. To begin with, therefore, both firms' quota demands satisfy

$$
B_{i}^{\prime}\left(q_{i}^{*}\right)=\frac{1}{\alpha_{i}} r, \quad i=1,2 .
$$

Now consider what happens if Firm 2, a net purchaser of quota, reduces $\gamma_{2}$ to $\gamma_{2}=\alpha_{2}<1$. The equilibrium quota price must then increase, since Firm 2 's quota demand curve becomes flatter as a result and therefore the industry inverse quota demand curve must become steeper. Because Firm 1's decision rule (11) remains the same, its output and therefore quota demand is reduced in response to the increased quota price and hence it now leases more quota to Firm 2, which expands its output. Firm 2's quota demand now satisfies

$$
B_{2}^{\prime}\left(q_{2}^{*}\right)=\frac{\gamma_{2}}{\alpha_{2}} r=r
$$

which implies $B_{2}^{\prime}\left(q_{2}^{*}\right)<B_{1}^{\prime}\left(q_{1}^{*}\right)$, which, if the firms are identical, confirms that now $q_{2}^{*}>q_{1}^{*}$. The result is nevertheless robust to heterogeneity in the fleet, as the numerical example in Section 5 illustrates.

In the new quota market equilibrium, Firm 1's owner benefits from increased quota leasing at an increased quota price, although his share of operating profits is reduced as the firm's output is reduced. Employing the Envelope Theorem, and using $Q_{1}^{*}=q_{1}^{*}$, from the Lagrangian for (3) we can find

$$
\frac{d \pi_{1}^{o}}{d r}=-\gamma_{1}\left[Q_{1}^{*}-\bar{Q}_{1}\right]>0,
$$

which is unambiguously positive for a net seller of quota. Firm 1's crew, on the other hand, clearly lose out since they only get a share of operating profits, which are reduced.

Firm 2 increases its output and hence total operating profits, and both the owner's and the crew's shares of operating profits are therefore increased. While total quota costs are unambiguously increased, these are now split between the owner and the crew. From

$$
\frac{d \pi_{2}^{o}}{d \gamma_{2}}=-r\left[Q_{2}^{*}-\bar{Q}_{2}\right]<0
$$

and

$$
\frac{d \pi_{2}^{o}}{d r}=-\gamma_{2}\left[Q_{2}^{*}-\bar{Q}_{2}\right]<0
$$

\footnotetext{
${ }^{6}$ Note that we continue to assume that there are a large number of competitive firms in the fishery: in effect, we consider one firm as representative of all net sellers of quota and the other as representative of all net purchasers of quota.
} 
we can see that, given $Q_{2}^{*}>\bar{Q}_{2}$, the owner of Firm 2 will benefit from a reduction in $\gamma_{2}$ but lose from an increase in the quota price $r$. Since we have seen that a reduction in $\gamma$ relative to $\alpha$ increases the owner's marginal willingness to pay for quota, however, it follows that the owner derives a net benefit from the change and hence we must have $-d \pi_{2}^{o} / d \gamma_{2}+d \pi_{2}^{o} / d r>0$. The total crew remuneration (profit share) for Firm 2 is given by

$$
\pi_{2}^{c} \equiv\left[1-\alpha_{2}\right] B_{2}\left(q_{2}^{*}\right)-\left[1-\gamma_{2}\right] r\left[Q_{2}^{*}-\bar{Q}_{2}\right]
$$

so that we can find

$$
\frac{d \pi_{2}^{c}}{d \gamma_{2}}=\left[\left[1-\alpha_{2}\right] B_{2}^{\prime}\left(q_{2}^{*}\right)-\left[1-\gamma_{2}\right] r\right] \frac{d q_{2}^{*}}{d \gamma_{2}}+r\left[Q_{2}^{*}-\bar{Q}_{2}\right]
$$

which again uses $Q_{2}^{*}=q_{2}^{*}$. Given that the owner ensures that $\alpha_{2} B_{2}^{\prime}\left(q_{2}^{*}\right)=\gamma_{2} r$, and that now we have $\alpha_{2}=\gamma_{2}$, this reduces to

$$
\frac{d \pi_{2}^{c}}{d \gamma_{2}}=r\left[Q_{2}^{*}-\bar{Q}_{2}\right]>0
$$

Similarly, we can find

$$
\frac{d \pi_{2}^{c}}{d r}=-\left[1-\gamma_{2}\right]\left[Q_{2}^{*}-\bar{Q}_{2}\right]<0
$$

Thus we confirm that a reduction in $\gamma_{2}$ and an increase in the quota price will lead to a reduction in crew remuneration for Firm 2. Finally, notice that while the total value of quota increases, the total economic profit in the fishery must decrease, since the allocation of quota is now inefficient.

\section{A numerical example}

We illustrate the results using a simple numerical example with two firms in the

fishery: one firm to represent all net sellers of quota and the other to represent all net quota purchasers. To give a specific functional form to equation (3), let

$$
\pi_{i}^{o} \equiv \alpha_{i}\left[p q_{i}-\frac{1}{2} c_{i} q_{i}^{2}\right]-\gamma_{i} r\left[Q_{i}-\bar{Q}_{i}\right], \quad i=1,2 .
$$

The first order conditions for the owners' optimal choices of $q_{i}^{*}=Q_{i}^{*}$ are then

$$
\alpha_{i}\left[p-c_{i} q_{i}^{*}\right]=\gamma_{i} r, \quad i=1,2 .
$$

Solving for $r$, and substituting using $\boldsymbol{Q} \equiv Q_{1}^{*}+Q_{2}^{*}=\bar{Q}_{1}+\bar{Q}_{2}$, we can employ a little manipulation to find

$$
Q_{1}^{*}=q_{1}^{*}=\frac{p\left[\frac{\alpha_{1}}{\gamma_{1}}-\frac{\alpha_{2}}{\gamma_{2}}\right]+\frac{\alpha_{2}}{\gamma_{2}} c_{2} \boldsymbol{Q}}{\frac{\alpha_{1}}{\gamma_{1}} c_{1}+\frac{\alpha_{2}}{\gamma_{2}} c_{2}},
$$


together with a similar expression for $Q_{2}^{*}$, as well as

$$
r=\frac{p \frac{\alpha_{1}}{\gamma_{1}}\left[c_{1}+c_{2}\right]-\frac{\alpha_{1}}{\gamma_{1}} c_{1} c_{2} \boldsymbol{Q}}{\frac{\alpha_{1}}{\gamma_{1}} \cdot \frac{\gamma_{2}}{\alpha_{2}} c_{1}+c_{2}} .
$$

Equations (22) and (23) together describe fully the quota market equilibrium. Given the parameters $p$ and $\bar{Q}_{i}$ as well as the cost coefficients $c_{i}$, we can then calculate the equilibrium quota market outcomes for any combination of the shares $\alpha_{i}$ and $\gamma_{i}$.

Let $p=\$ 10,000, \bar{Q}_{1}=100$ tonnes and $\bar{Q}_{2}=20$ tonnes, so that $\boldsymbol{Q}=120$ tonnes, with $c_{1}=0.1$ and $c_{2}=0.05$. Notice that we have now relaxed the assumption that the firms are identical: here Firm 2 is clearly more efficient than Firm 1, although its initial quota endowment is smaller.

Table I shows the quota market outcome when $\alpha_{1}=\alpha_{2}=0.5$ and $\gamma_{1}=$

$\gamma_{2}=1$. Firm 1 leases 60 tonnes of quota to Firm 2 at an equilibrium price of $\$ 3,000$. Total economic profits in the fishery are $\$ 960,000$, of which $\$ 360,000$ is captured in the value of quota. In Table II, we show the results when both $\gamma_{i}$ shares are reduced to equal the $\alpha_{i}$ shares. Notice that the (efficient) quota allocation is unchanged, as are the total economic profits in the fishery. Now, however, the value of quota is doubled and the impact of this is entirely felt by the crew. The crew of Firm 1 more than double their income (from $\$ 160,000$ to $\$ 340,000)$ while the crew of Firm 2 see their total remuneration reduced from $\$ 320,000$ to $\$ 140,000$.

Table III shows the outcome when only Firm 2 reduces $\gamma_{2}$ to equal $\alpha_{2}$, while Firm 1 retains $\gamma_{1}=1$. Compared to the outcome in Table I, we can see that although the total value of quota is increased, total profits in the fishery are reduced since the quota allocation is now inefficient. The owner of Firm 1 gains as a result of the increased leasing of quota to Firm 2, but Firm 1's crew lose out. As predicted, there is also a net gain for the owner of Firm 2, while the crew of Firm 2 suffer a net loss in income.

\section{Conclusion}

We have shown that, all else equal, changes in the share of quota costs paid by the firm owner, when undertaken symmetrically across the whole fleet, have an impact upon the equilibrium quota price but do not change the owner's total profit share. The effects of changes in the quota price fall entirely upon the crew, who gain or lose a share of profits as a result. We have also seen that the efficiency of quota allocation is maintained as long as the owners' shares of quota costs and operating profits are consistent across the fleet: there is no requirement for these shares to be equal.

Given this, if the fixed (capital) costs of the firm are paid from the owner's share of the total profits, as is usually the case, there appear to be no implications for long run efficiency if there are changes across the fleet in the owners' 
share of quota costs. A positive crew reservation wage on the other hand, which represents a quasi-fixed cost to be covered by the crew's share of operating profits, would impose an upper limit on the percentage of quota costs which can be borne by the crew. We have assumed, however, that labour's reservation wage is exogenous to the fishery in question. We have also assumed, in our analysis of the effects of changes in quota shares, that this remuneration constraint is never binding. We have further assumed that changes in crew shares do not affect their incentives for effort and hence (in our model) harvesting costs. Throughout, labour retains a share in marginal profits and we would not therefore expect any fundamental change in the incentive structure of the labour contract.

If only some firm owners share quota costs with the crew (and we assumed that net sellers of quota might be reluctant to do so) we saw that quota allocation would no longer be efficient and that total economic profits in the fishery would be reduced as a result. Nevertheless, the equilibrium quota price would still increase, and all firm owners would benefit at the expense of their crews.

Although there seems to be a widespread, if not universal, reluctance on behalf of the governments of fishing nations to attempt to extract resource rents from the industry, a share system which effectively increases the proportion of economic profits which are reflected in the value of quota has interesting implications for rent capture policies (see, for example, Grafton, 1992; 1995). At the very least, the generation of rents in the fishery is more accurately measured than in a share fishery where crew do not share in the cost of quota, since a part of the surplus previously paid to the crew is now transferred to the value of quota. In consequence, a tax on quota value, for example, would have the potential to capture a greater proportion of the rents generated in the fishery.

Finally, just as we have not addressed the evolution and persistence of fisheries share systems in general, a subject which has been well covered elsewhere (see, for example, McConnell and Price, 2006), so we have left to one side the process by which changes in quota shares might be negotiated. The bargaining aspects of this could be a fruitful area for future investigation. 


\section{References}

Abbott, J. K., B. Garber-Yonts and J. E. Wilen, 2010. Employment and remuneration effects of IFQs in the Bering Sea/Aleutian Islands crab fisheries. Marine Resource Economics, 25: 333-354.

Anderson, L. G., 1982. The share system in open access and optimally regulated fisheries. Land Economics, 58: 435-449.

Anderson, L. G., 1999. ITQs in share system fisheries: implications for efficiency, distribution and tax policy. In: R. Arnason and H. H. Gissurarson, eds., Individual Transferable Quotas in Theory and Practice. Reykjavik: University of Iceland Press, p.169-184.

Grafton, R. Q., 1992. Rent capture in an individual transferable quota fishery. Canadian Journal of Fisheries and Aquatic Sciences, 49: 497-503.

Grafton, R. Q., 1995. Rent capture in a rights-based fishery. Journal of Environmental Economics and Management, 28: 48-67.

Hannesson, R., 2000. A note on ITQs and optimal investment. Journal of Environmental Economics and Management, 40: 181-188.

Matthiasson, T., 1999. Cost sharing and catch sharing. Journal of Development Economics, 58: 25-44.

McConnell, K. E., and M. Price, 2006. The lay system in commercial fisheries: origin and implications. Journal of Environmental Economics and Management, 51: 295-307.

Pinkerton, E., and D. N. Edwards, 2009. The elephant in the room: the hidden costs of leasing individual transferable fishing quotas. Marine Policy, 33: 707-713.

Sutinen, J. G., 1979. Fishermens' remuneration systems and implications for fisheries development. Scottish Journal of Political Economy, 26: 146-162. 


\begin{tabular}{|c|c|c|c|c|c|c|}
\hline & & Firm 1 & & & Firm 2 & \\
\hline & $\alpha_{1}=0.5$ & $\gamma_{1}=1.0$ & $Q_{1}^{*}=40$ & $\alpha_{2}=0.5$ & $\gamma_{2}=1.0$ & $Q_{2}^{*}=80$ \\
\hline & Total & Owner & Crew & Total & Owner & Crew \\
\hline$B\left(q_{i}^{*}\right)$ & 320 & 160 & 160 & 640 & 320 & 320 \\
\hline$-r\left[Q_{i}^{*}-\bar{Q}_{i}\right]$ & 180 & 180 & 0 & -180 & -180 & 0 \\
\hline$B\left(q_{i}^{*}\right)-r\left[Q_{i}^{*}-\bar{Q}_{i}\right]$ & 500 & 340 & 160 & 460 & 140 & 320 \\
\hline$\sum_{i=1}^{2} B\left(q_{i}^{*}\right)=960$ & $r=3$ & & & & & \\
\hline
\end{tabular}

Table I. Owners bear $100 \%$ of quota costs (in $\$ 000$ ) 


\begin{tabular}{lcccccc}
\hline \hline & & Firm 1 & & & Firm 2 & \\
& $\alpha_{1}=0.5$ & $\gamma_{1}=0.5$ & $Q_{1}^{*}=40$ & $\alpha_{2}=0.5$ & $\gamma_{2}=0.5$ & $Q_{2}^{*}=80$ \\
& Total & Owner & Crew & Total & Owner & Crew \\
& 320 & 160 & 160 & 640 & 320 & 320 \\
$B\left(q_{i}^{*}\right)$ & 360 & 180 & 180 & -360 & -180 & -180 \\
$-r\left[Q_{i}^{*}-\bar{Q}_{i}\right]$ & 680 & 340 & 340 & 280 & 140 & 140 \\
$B\left(q_{i}^{*}\right)-r\left[Q_{i}^{*}-\bar{Q}_{i}\right]$ & & & & & & \\
\hline$\sum_{i=1}^{2} B\left(q_{i}^{*}\right)=960$ & $r=6$ & & & & & \\
\hline \hline
\end{tabular}

Table II. Owners bear $50 \%$ of quota costs (in $\$ 000$ ) 


\begin{tabular}{lrrrrrr}
\hline \hline & & Firm 1 & & & Firm 2 & \\
& $\alpha_{1}=0.5$ & $\gamma_{1}=1.0$ & $Q_{1}^{*}=10$ & $\alpha_{2}=0.5$ & $\gamma_{2}=0.5$ & $Q_{2}^{*}=110$ \\
& Total & Owner & Crew & Total & Owner & Crew \\
& 95 & 47.5 & 47.5 & 797.5 & 398.75 & 398.75 \\
$B\left(q_{i}^{*}\right)$ & 405 & 405 & 0 & -405 & -202.5 & -202.5 \\
$-r\left[Q_{i}^{*}-\bar{Q}_{i}\right]$ & 500 & 452.5 & 47.5 & 392.5 & 196.25 & 196.25 \\
$B\left(q_{i}^{*}\right)-r\left[Q_{i}^{*}-\bar{Q}_{i}\right]$ & & & & & & \\
\hline$\sum_{i=1}^{2} B\left(q_{i}^{*}\right)=892.5$ & $r=4.5$ & & & & & \\
\hline \hline
\end{tabular}

Table III. Buyers bear $50 \%$ of quota costs; sellers keep $100 \%$ of quota income (in $\$ 000$ ) 